\title{
Focal Breast Lesions in Clinical CT Examinations of the Chest: A Retrospective Analysis
}

\section{Senologische Befunde bei CT-Untersuchungen des Thorax: eine retrospektive Auswertung}

Authors

Kathrin Barbara Krug${ }^{1}$, Christian Houbois ${ }^{1}$, Olga Grinstein¹, Jan Borggrefe ${ }^{1}$, Michael Puesken ${ }^{1}$, Bettina Hanstein², Wolfram Malter ${ }^{2}$, David Maintz ${ }^{1}$, Martin Hellmich ${ }^{3}$

Affiliations

1 Dept. of Diagnostical and Interventional Radiology, University of Cologne Medical School, Cologne, Germany

2 Breast Center and Dept. of Obstetrics and Gynecology, University of Cologne Medical School, Cologne, Germany

3 Institute of Medical Statistics, Informatics and Epidemiology, University of Cologne, Germany

Key words

breast, $\mathrm{CT}$, breast cancer, metastases

received 17.11.2016

accepted 22.05.2017

\section{Bibliography}

DOI https://doi.org/10.1055/s-0043-112749

Published online: 6.7.2017 | Fortschr Röntgenstr 2017; 189: 977-988 @ Georg Thieme Verlag KG, Stuttgart · New York, ISSN 1438-9029

\section{Correspondence}

Prof. Kathrin Barbara Krug

Institut für Radiologische Diagnostik, Klinikum der Universität zu Köln, Joseph-Stelzmann-Str. 9, 50931 Köln, Germany

Tel.: ++49/2 21/4785661

Fax: ++ 49/2 21/4785661

barbara.krug@uk-koeln.de

\section{ABSTRACT}

Purpose Based on radiological reports, the percentage of breast cancers visualized as incidental findings in routine CT examinations is estimated at $\leq 2 \%$. In view of the rising number of CT examinations and the high prevalence of breast cancer, it was the goal of the present study to verify the frequency and image morphology of false-negative senological CT findings.

Materials and Methods All first contrast-enhanced CT examinations of the chest in adult female patients carried out in 2012 were retrospectively included. A senior radiologist systematically assessed the presence of breast lesions on all $\mathrm{CT}$ images using the BI-RADS system. All BI-RADS $\geq 3$ notations were evaluated by a second senior radiologist. A consensus was obtained in case of differing BI-RADS assessments.
Reference diagnoses were elaborated based on all available clinical, radiological and pathological data. The findings of the $\mathrm{CT}$ reports were classified according to the BI-RADS system and were compared with the retrospective consensus findings as well as with the reference diagnoses.

Results The range of indications comprised a broad spectrum including staging and follow-up examinations of solid tumors/lymphoma ( $N=701,59.9 \%)$ and vascular (190, $16.2 \%)$, inflammatory $(48,4.1 \%)$ and pulmonologic (22, $1.9 \%$ ) issues. BI-RADS $1 / 2$ classifications were present in $92.5 \%$ and BI-RADS 6 classifications were assessed in $1.7 \%$ of the 1170 included examinations. 68 patients (5.8\%) had at least one lesion retrospectively classified as BI-RADS 3-5. The histological potential was known in 57 of these lesions as benign $(46,3.9 \%$ ) or malignant (11, $0.9 \%) .13$ BI-RADS $4 / 5$ consensus assessments ( $1.1 \%$ ) were false-positive. 2 of the 10 lesions classified as being malignant based on the further clinical and radiological course were not mentioned in the written CT reports $(0.2 \%)$. Both false-negative CT reports were therapeutically and prognostically irrelevant.

Conclusion The relative frequency of BI-RADS $3-5$ findings was $5.8 \%$. It reflects the situation encountered in clinical imaging for primarily non-senologic questions and therefore differs from what would be expected in a dedicated screening program. The rates of known false-positive BI-RADS 4/5 findings in the retrospective evaluations (1.1\%) and of false-negative findings in the written $\mathrm{CT}$ reports $(0.2 \%)$ reflect the different diagnostic approaches of image-based senological screening and radiological examinations indicated in order to solve clinical problems not primarily concerning the breast region. Statements regarding the prevalence of clinically occult breast cancers can only be made with caution in the presented, highly selective group of patients due to the often incomplete visualization of breast tissue and the retrospective approach.

\section{Key points}

- Intramammary mass and non-mass lesions needing clarification may be present in up to $5.8 \%$ of all contrast enhanced CT-examinations of the female chest.

- Irregular forms, unscharp/spiculated margins, inhomogeneous matrices and a pronounced contrast medium en- 
hancement point towards a malignant genesis of an intramammary mass or non-mass lesion.

- The results of the study highlight the importance of paying systematical and targeted attention on senological additional findings in CT-examinations of the chest also in other clinical settings than that of the included patients in a clinic with oncological main focus.

\section{Zitierweise}

- Krug KB, Houbois C, Grinstein O et al. Focal Breast Lesions in Clinical CT Examinations of the Chest: A Retrospective Analysis. Fortschr Röntgenstr 2017; 189: 977-988

\section{ZUSAMMENFASSUNG}

Ziel Die Rate inzidenteller Mammakarzinomen bei CT-Untersuchungen wird basierend auf Auswertungen der Befundberichte mit $\leq 2 \%$ beziffert. Wegen der ansteigenden Frequenz von CT-Untersuchungen und der hohen Prävalenz von Mammakarzinomen sollten Häufigkeit und Art senologisch falsch negativer CT-Befunde auf der Basis retrospektiver Bildauswertungen überprüft werden.

Material und Methoden Alle erstmalig im Jahre 2012 durchgeführten KM-gestützten CT-Untersuchungen des Thorax bei volljährigen Patientinnen wurden retrospektiv eingeschlossen. Ein Radiologe wertete alle Bilddokumentationen nach BI-RADS hinsichtlich senologischer Herdbefunde aus. Alle BI-RADS $\geq 3$ Einstufungen wurden von einem 2. Auswerter überprüft und bei divergierender Einschätzung im Konsens besprochen. Basierend auf allen klinischen, radiologi- schen und pathologischen Angaben wurden Referenzdiagnosen erarbeitet. Die senologischen Informationen der Befundberichte wurden retrospektiv nach BI-RADS klassifiziert und mit den retrospektiven Konsensauswertungen und den Referenzdiagnosen abgeglichen.

Ergebnisse Das Spektrum der Indikationen umfasste Staging und Verlaufskontrollen von soliden Organtumoren/Lymphomen ( $N=701,59,9 \%)$ sowie vaskuläre $(190,16,2 \%)$, entzündliche $(48,4,1 \%)$ und pneumologische $(22,1,9 \%)$ Fragestellungen. BI-RADS $1 / 2$ Befunde lagen bei $92,5 \%$ und BI-RADS 6 Befunde bei $1,7 \%$ der 1170 Untersuchungen vor. Bei 68 Untersuchungen (5,8\%) wurden retrospektiv BI-RADS 3 - 5 Befunde beschrieben, die in 57 Fällen als benigne (46; 3,9\%) oder maligne (11;0,9\%) einzustufen waren. 13 BI-RADS 4/5 Einstufungen $(1,1 \%)$ der Konsensauswertungen waren falsch positiv. Die beiden gesicherten falsch negativen CT-Befunde $(0,2 \%)$ waren therapeutisch und prognostisch nicht relevant. Schlussfolgerung Bei der kurativen Diagnostik überwiegend nicht senologischer Fragestellungen betrug die relative Häufigkeit von BI-RADS 3 - 5 Befunden 5,8\%. Die Raten gesicherter falsch positiver retrospektiver BI-RADS 4/5-Befunde $(1,1 \%)$ und falsch negativer CT-Befundberichte $(0,2 \%)$ weichen naturgemäß von Werten aus einem senologischen Screening ab. Aussagen zur Prävalenz des okkulten Mammakarzinoms sind aufgrund des selektierten Kollektivs, der teils unvollständigen Parenchymerfassung und des retrospektiven Ansatzes nur mit Einschränkungen möglich.

\section{Introduction}

$\mathrm{CT}$ examinations of the chest are being increasingly performed worldwide for diagnostic purposes in basic patient care. Incidental findings such as coronary calcification, bronchiectasis, pulmonary emphysema, degenerative spinal column changes, and liver cysts are common and are described in up to $73 \%$ of all CT examinations depending on the patient population. In contrast, the frequency of incidental breast findings relevant to treatment and prognosis in CT examinations of the chest is controversial due to a lack of epidemiological data [2-7]. Multiple retrospective studies came to the conclusion that previously undetected, organ-specific, systemic, or metastatic malignancies in the breast visible on computed tomography can be expected in up to $1.9 \%$ (8) of all CT examinations of the chest [3, 6, 9-11]. In light of this, targeted evaluation of the female breast in CT examinations of the chest has the potential to be used for secondary preventative care [6]. Statements regarding the frequency of incidental senological CT findings published to date are all based on retrospective evaluations of written reports electronically stored in hospital information systems (HIS) $[2-6,8,10]$. To the authors' knowledge, there are not yet any retrospective CT examination analyses independent of the written reports and the clinical history and based on the image documentation. A representative systematic classification of the constellations of CT findings analogous to the radiologic, sonographic, and MR-mammographic BIRADS lexicon is currently not available. Therefore, the percentage of senological lesions morphologically visible on CT may be higher with targeted evaluation of the breast region than in the retrospective analysis of diagnostic data extracted from written reports. The incidence and the differential diagnostic constellations of findings of benign incidental CT findings in the breast have also not been systematically analyzed. Therefore, the goal of the present study is to answer the following questions.

- How high is the percentage of BI-RADS 3-5 CT findings in CT examinations of the chest on the basis of an analysis of the image documentation blinded to the written reports and the further clinical-radiological course?

- Were the BI-RADS 3 - 5 findings determined in the retrospective image evaluation mentioned in the written reports? If yes, what were the diagnostic and/or therapeutic consequences?

- What effect did the retrospectively recorded BI-RADS 3 - 5 findings have on treatment and prognosis? 


\section{Materials and Methods}

\section{Inclusion and exclusion criteria}

The study was approved by the responsible local ethics committee. All patients aged $\geq 18$ years who underwent CT examination of the chest after i.v. contrast administration on one of the two CT units at the radiology institute between 1/1/2012 and 12/31/ 2012 were included in the image assessments. All male patients and all female patients aged $<18$ years, all follow-up CT examinations performed in 2012, and all CT examinations without i.v. contrast administration were excluded.

\section{Patient and examination data}

Patient and examination data were obtained by performing an interactive electronic query of the radiology information system of the university hospital (RIS Nice ${ }^{\circledR}$, AGFA HealthCare, NV, Mortsel, Belgium) using the search parameters „CT chest“ and „CT chest/abdomen“. All CT examinations fulfilling the inclusion criteria and not the exclusion criteria were interactively entered in a table (Excel ${ }^{\circledR}$, Microsoft Corp., Redmond, WA, USA). Image data acquisition and reconstruction parameters were recorded interactively. The clinical history and the radiological course of patients with findings in the breast were obtained from the hospital information system (HIS) (ORBIS $^{\circledR}$ OpenMed, AGFA HealthCare, NV, Mortsel, Belgium) and the picture archiving and communication system (PACS) (ImpaxEE ${ }^{\circledR}$, AGFA Healthcare, NV, Mortsel, Belgium) of the university hospital.

\section{CT examination technique}

Examinations were performed using the $\mathrm{CT}$ systems Brilliance iCT and Brilliance 64 (Philips Healthcare, Eindhoven, Netherlands). Tube voltages of $100 \mathrm{kV}$ and $120 \mathrm{kV}$, respectively, were used. The tube current intensity varied between $100 \mathrm{mAs}$ and $300 \mathrm{mAs}$. The acquired slice thickness was $1 \mathrm{~mm}$ with a slice overlap of $1 \mathrm{~mm}$. Transverse thin-slice image series with a reconstruction slice thickness of $1 \mathrm{~mm}$ or $2 \mathrm{~mm}$ and transverse image series with a reconstruction slice thickness of $4 \mathrm{~mm}$ with a soft tissue window (window $360 \mathrm{HU}$, level $60 \mathrm{HU}$ ), lung window (window $1300 \mathrm{HU}$, level $-500 \mathrm{HU}$ ) and bone window (window $1720 \mathrm{HU}$, level 530 $\mathrm{HU}$ ) were available for all CT examinations stored in the PACS. Additional image reconstructions with a slice thickness of $5 \mathrm{~mm}$ in a coronal (soft tissue window) and sagittal slice orientation (soft tissue window and bone window) were available in the PACS for some of the CT examinations. Reformatting with any desired spatial direction, slice thickness, and windowing was able to be performed interactively on the image evaluation console as needed.

Iohexol $^{\circledR}$ (Accupaque $350^{\mathrm{TM}}$, GE Healthcare Buchler, Fairfield, USA) in a standard dose of $60 \mathrm{ml}$ (examination region: chest) or $100 \mathrm{ml}$ (examination region: chest/abdomen) was used as the intravenous contrast agent. The contrast agent was administered via a high-pressure injector pump (Accutron $\mathrm{CTD}^{\circledR}$ or $\mathrm{CT} 2^{\circledR}$, Medrad Medizinische Systeme $\mathrm{GmbH}$, Leverkusen, Germany) via a peripheral or central-venous access with injection rates of $3-5 \mathrm{ml} / \mathrm{s}$ adjusted to the particular clinical issue and the scan protocol. Data was acquired in the time interval stored in the scan protocol.

\section{Image assessment}

Image documentation was retrospectively evaluated on a dedicated HIS-PACS workstation (ImpaxEE ${ }^{\circledR}$, AGFA Healthcare, NV, Mortsel, Belgium). Transverse slices with small reconstruction slice thicknesses of $1 \mathrm{~mm}$ in the soft tissue window were used. All evaluation options of the image evaluation console including electronic zoom were available.

All 1170 CT examinations fulfilling the inclusion criteria were evaluated in a first step in an electronic data collection form by a radiologist (C.H. or J.B.) with knowledge of the electronically stored clinical issue. The written reports and the radiological, histological, and clinical documents stored in the electronic patient file were not viewed during this evaluation in order to simulate a primary image evaluation. Whether the breast region was completely or only partially included in the reconstructed image datasets was documented for each side (degree of capture $0 \%$ to $<33 \%, 33 \%$ to $<66 \%, 66 \%$ to $100 \%$ ). The density of the parenchyma was categorized according to the ACR Classification ${ }^{\circledR}$ of the American College of Radiology (ACR) for X-ray and MR mammography [12]. The findings were categorized separately for each side according to the BI-RADS Classification ${ }^{\circledR}$ of the American College of Radiology (ACR) using the stages BI-RADS 1 through BI-RADS 6. BI-RADS 1 to BI-RADS 5 categorizations were assigned on the basis of $C T$ features. Ipsilateral intramammary lesions on CT examinations performed according to the clinical issue for the purpose of staging or surgical preparation in patients with a newly diagnosed breast carcinoma were classified as BI-RADS 6. Every identified lesion was characterized analogously to the procedure used for MR-mammographic findings regarding the criteria „size“ (mm), „shape“ (round-oval, lobulated, irregular), „margin“ (smooth, unsharp, spiculated), „matrix“ (homogeneous, inhomogeneous), „internal calcifications“, „density“, (Hounsfield units, $\mathrm{HU}$ ), and the ratio of the density of the lesion to the density of the pectoral muscle.

All findings classified as BI-RADS $\geq 3$, every 10 th of the BI-RADS 2 classifications, and about every 30th of the BI-RADS 1 classifications were evaluated in a 2 nd step by a radiologist with many years of experience in senological and CT imaging (B.K.) with knowledge of the previously assigned BI-RADS classifications using the same approach. Differences in classifications were resolved together with one of the two primary evaluators (C.H.) in consensus (retrospective consensus assessment).

The CT findings recorded with the electronic data collection form were compared to clinical, radiological and histological data and documents stored in the HIS and RIS of the hospital in a 3 rd step (J.B., O.G., B.H., B.K., W.M.). If CT follow-up examinations were available, the dynamics of the lesion retrospectively diagnosed in the index examination in $\mathbf{2 0 1 2}$ were evaluated. For the further statistical analysis, the diagnostic statements contained in the written reports of the index examinations were retrospectively classified according to BI-RADS. 


\section{Statistical analysis}

The data were recorded in a standardized input screen (Excel ${ }^{\circledR}$, Microsoft Corp., Redmond, WA, USA). Quantitative variables were provided with the average, standard deviation, median, minimum and maximum, while qualitative variables were specified with the absolute and relative frequency (\%). Box plots and column diagrams were used for graphic representation. Pairwise relationships and group comparisons were evaluated with the Fisher's exact test and the Mann-Whitney U-Test. A p-value $\leq 0.05$ was considered statistically significant. A correction for multiple comparisons was not performed. The statistical analyses were performed with the program SPSS Statistics (IBM Corp., Armonk, NY, USA).

\section{Results}

\section{Clinical history and examination data}

$1170 \mathrm{CT}$ examinations met the inclusion criteria ( $\triangleright$ Table 1$)$. The average age of the included patients was 60 years \pm 17 years standard deviation (minimum 18 years, maximum 94 years). According to the oncological focus of the university hospital, the most common indications were staging, treatment monitoring and follow-up of solid organ tumors and malignant lymphomas (701 of the 1170 patients, $60.0 \%$ ), vascular issues (190 patients; $16.2 \%$ ), and inflammatory or interstitial pulmonary diseases (70 patients; $6.0 \%$ ). 32 patients (2.7\%) had 2 primary diseases and 2 patients $(0.2 \%)$ had 3 primary diseases.

$75-100 \%$ visualization of the right breast was achieved in 985 CT examinations $(84.1 \%$ ) and of the left breast in 975 CT examinations ( $83.4 \%$ ). $50 \%-<75 \%$ visualization of the breast was achieved 86 times $(7.4 \%)$ on the right side and 89 times $(7.6 \%)$ on the left side, $25 \%-50 \%$ visualization 96 times $(8.2 \%)$ on the right side and 100 times $(8.5 \%)$ on the left side, and $0 \%-<25 \%$ visualization 3 times $(0.3 \%)$ on the right side and 6 times $(0.5 \%)$ on the left side. 37 patients (3.2\%) had undergone ablation of the right breast and 24 patients ( $2.1 \%$ ) of the left breast. ACR density category 2 (right breast 544 times, $46.5 \%$; left breast 560 times, $47.9 \%$ ) was seen more often than density categories 1 (right breast 166, $14.2 \%$; left breast 164, $14.0 \%$ ), 3 (right breast 237 , $20.3 \%$; left breast 236, 20.2\%) and 4 (right breast 186, $15.9 \%$; left breast 186, 15.9\%).

In the primary evaluation, 924 images of the right breast (79.0\%) and 940 images of the left breast (80.3\%) were categorized as BI-RADS 1 and 171 images of the right breast (14.6\%) or 181 images of the left breast (13.8\%) as BI-RADS 2. 52 examinations of the right breast (4.4\%) and 57 examinations of the left breast $(4.9 \%$ ) were classified as requiring further diagnostic workup (BI-RADS $3-5$ ) or were histologically confirmed as malignant (BI-RADS 6). 8 of these findings (0.7\%) were bilateral. $88 \mathrm{CT}$ examinations with BI-RADS $\geq 3$ classifications per patient $(7.5 \%)$ were selected in consensus for further statistical analysis. 13 patients were downgraded to BI-RADS 1 or 2 in consensus

\section{$(\triangleright$ Table 1$)$.}

The differential diagnosis was confirmed in 77 of the 88 lesions (87.5\%) by histology (22; $25.0 \%$ ), senological workup (breast
- Table 1 Medical histories, degree of breast coverage and the BI-RADS classifications in all $1170 \mathrm{CT}$ examinations of the chest. Two primary diseases were documented for 32 patients (2.7\%) and 3 primary diseases for 2 patients ( $0.2 \%$ ).

\begin{tabular}{|c|c|c|}
\hline & $\mathbf{n}$ & $\%$ \\
\hline \multicolumn{3}{|l|}{ primary disease (1170 patients) } \\
\hline staging in breast carcinoma & 93 & 8.0 \\
\hline follow-up of a breast carcinoma & 13 & 1.1 \\
\hline $\begin{array}{l}\text { staging, treatment monitoring and follow- } \\
\text { up of other solid organ tumors }\end{array}$ & 422 & 36.1 \\
\hline $\begin{array}{l}\text { staging/treatment monitoring of malig- } \\
\text { nant lymphomas }\end{array}$ & 173 & 14.8 \\
\hline inflammatory pulmonary diseases & 48 & 4.1 \\
\hline interstitial pulmonary diseases & 22 & 1.9 \\
\hline vascular diseases & 190 & 16.2 \\
\hline other & 237 & 20.3 \\
\hline \multicolumn{3}{|c|}{ BI-RADS consensus classifications (1170 patients) } \\
\hline $1 \& 2$ & 1082 & 92.5 \\
\hline$\geq 3$ & 88 & 7.5 \\
\hline \multicolumn{3}{|l|}{ verification of diagnosis (88 patients) } \\
\hline biological significance known & 78 & 88.6 \\
\hline histological verification & 22 & 25.0 \\
\hline $\begin{array}{l}\text { senologic-sonographic, X-ray-mammo- } \\
\text { graphic, and/or MR-mammographic } \\
\text { workup }\end{array}$ & 10 & 11.4 \\
\hline CT and/or clinical course of $>1$ year & 46 & 52.2 \\
\hline $\begin{array}{l}\text { retrospective verification of diagnosis not } \\
\text { possible }\end{array}$ & 10 & 11.4 \\
\hline \multicolumn{3}{|c|}{ biological classification of $\mathrm{CT}$ lesions (88 patients) } \\
\hline benign & 46 & 52.3 \\
\hline malignant & 31 & 35.2 \\
\hline unknown & 11 & 12.5 \\
\hline
\end{tabular}

ultrasound, X-ray mammography or MR mammography) (9; $10.2 \%)$ or CT $(46 ; 52.3 \%)$ and/or clinical follow-up for at least 1 year. The biological significance of 10 of 88 lesions $(8.8 \%$ ) could not be determined retrospectively since no or only insufficient follow-up was stored in the patient files. 46 of 88 lesions ( $52.3 \%$ ) were able to be retrospectively classified as benign. 20 lesions (22.7\%) were already histologically verified as breast carcinomas prior to the index CT examination. 11 lesions were histologically diagnosed as malignant after the index CT examination. 7 patients $(8.0 \%$ ) had breast carcinomas, 3 patients (3.4\%) had intramammary metastases of other organ tumors, and 1 patient had malignant intramammary lymphoma (1.1\%).

\section{BI-RADS analyses and carcinoma incidence}

In Table $>2$ the BI-RADS classifications of the retrospective consensus evaluations are compared to the reports of the CT findings for all 88 CT examinations with retrospective BI-RADS $\geq 3$ classifi- 
- Table 2 Tabular comparison of the retrospective consensus evaluations with the reports of the CT findings for all 88 CT examinations with retrospective BI-RADS $\geq 3$ consensus classifications separately for the 46 CT examinations with benign lesions, the 31 CT examinations with malignant lesions and the 11 CT examinations without verification of diagnosis.

\begin{tabular}{|c|c|c|c|c|c|c|c|c|c|}
\hline \multicolumn{2}{|c|}{ biological significance } & \multirow[b]{2}{*}{ BI-RADS } & \multicolumn{6}{|c|}{ consensus finding } & \multirow[t]{2}{*}{ total } \\
\hline & & & 1 & 2 & 3 & 4 & 5 & 6 & \\
\hline \multirow[t]{7}{*}{ benign } & report & 1 & 0 & 0 & 28 & 7 & 1 & 0 & 36 \\
\hline & & 2 & 0 & 0 & 1 & 2 & 0 & 0 & 3 \\
\hline & & 3 & 0 & 0 & 0 & 0 & 0 & 0 & 0 \\
\hline & & 4 & 0 & 0 & 4 & 3 & 0 & 0 & 7 \\
\hline & & 5 & 0 & 0 & 0 & 0 & 0 & 0 & 0 \\
\hline & & 6 & 0 & 0 & 0 & 0 & 0 & 0 & 0 \\
\hline & & total & 0 & 0 & 33 & 12 & 1 & 0 & 46 \\
\hline \multirow[t]{7}{*}{ malignant } & & 1 & 0 & 0 & 0 & 0 & 2 & 0 & 2 \\
\hline & & 2 & 0 & 0 & 0 & 0 & 0 & 0 & 0 \\
\hline & & 3 & 0 & 0 & 0 & 0 & 0 & 0 & 0 \\
\hline & & 4 & 0 & 0 & 0 & 0 & 2 & 0 & 2 \\
\hline & & 5 & 0 & 0 & 0 & 0 & 7 & 0 & 7 \\
\hline & & 6 & 0 & 0 & 0 & 0 & 0 & 20 & 20 \\
\hline & & total & 0 & 0 & 0 & 0 & 11 & 20 & 31 \\
\hline \multirow[t]{7}{*}{ unclear } & & 1 & 0 & 0 & 3 & 6 & 1 & 0 & 10 \\
\hline & & 2 & 0 & 0 & 0 & 1 & 0 & 0 & 1 \\
\hline & & 3 & 0 & 0 & 0 & 0 & 0 & 0 & 0 \\
\hline & & 4 & 0 & 0 & 0 & 0 & 0 & 0 & 0 \\
\hline & & 5 & 0 & 0 & 0 & 0 & 0 & 0 & 0 \\
\hline & & 6 & 0 & 0 & 0 & 0 & 0 & 0 & 0 \\
\hline & & total & 0 & 0 & 3 & 7 & 1 & 0 & 11 \\
\hline total & & & 0 & 0 & 36 & 19 & 13 & 20 & 88 \\
\hline
\end{tabular}

cations separated according to the classification of the reference diagnoses. A histologically verified breast carcinoma was present at the time of CT examination (BI-RADS 6) in 20 of 88 CT examinations (22.3\%). 9 of 11 breast tumors confirmed as malignant by diagnostic CT imaging $(0.8 \%$ of 1170 total CT examinations and $10.2 \%$ of the 88 CT examinations with BI-RADS $\geq 3$ classifications in the consensus evaluations) were correctly described as requiring further workup in the written reports. 2 cases classified as BI-RADS 5 in the consensus evaluations $(0.2 \%$ or $2.3 \%$ of the 88 CT examinations) were overlooked in the diagnostic evaluation of the images as evidenced by the written reports. This affected 2 patients in advanced stages of oncological disease who had undergone adequate additional senological diagnosis and treatment independently of the false-negative CT diagnoses so that the false-negative findings were without therapeutic or prognostic consequence ( $\triangleright$ Table 3 ). Both findings were probably overlooked during the diagnostic CT evaluations due to their small size ( $\triangleright$ Fig. 1) and the multitude of metastases in the other examined organ regions ( $\mathbf{F i g} . \mathbf{2}$ ).

In the retrospective consensus evaluations, 12 of the 46 lesions diagnosed as benign according to the reference diagnoses were classified as BI-RADS 4 (13.6\% of the 88 CT examinations with BI-RADS $\geq 3$ classifications) and 1 lesion as BI-RADS 5 (1.1\%). The classification as benign was based on senologic-sonographic and $\mathrm{X}$-ray mammographic examinations performed at the same time as the index CT in 6 of 14 patients with false-positive consensus evaluations, on consistent findings at > 1-year CT follow-up examinations in 5 patients, and on normal clinical follow-up examinations of the breast at $>1$ year in 4 patients ( $\triangleright$ Table 4 ).

\section{Image analysis of the lesions}

The validity of the CT evaluation criteria for determining malignancy was analyzed in the 77 lesions with verified differential diagnosis or known biological potential ( $\vee$ Fig. 3,4$)$. With a median maximum diameter of $8 \mathrm{~mm}$ (minimum $3 \mathrm{~mm}$, maximum $25 \mathrm{~mm}$ ), benign lesions were statistically noticeably smaller than malignant lesions with a median maximum diameter of $24 \mathrm{~mm}$ $(5 \mathrm{~mm}, 98 \mathrm{~mm})(\mathrm{p}<0.001)$. A round shape was observed more frequently in benign lesions, while an irregular shape was most commonly seen in malignant processes $(p<0.004)$. A smooth margin and a homogeneous matrix were more commonly seen 
- Table 3 Verification of the reference diagnoses in the 13 patients with false-positive consensus classifications and both patients with false-negative written CT reports.

\begin{tabular}{|c|c|c|c|c|c|c|}
\hline no. & $\begin{array}{l}\text { age } \\
\text { (years) }\end{array}$ & $\begin{array}{l}\text { consensus eva- } \\
\text { luations } \\
\text { (BI-RADS) }\end{array}$ & $\begin{array}{l}\text { reports } \\
\text { (BI-RADS) }\end{array}$ & $\begin{array}{l}\text { biological } \\
\text { potential }\end{array}$ & $\begin{array}{l}\text { verification of } \\
\text { diagnosis }\end{array}$ & course of disease \\
\hline \multicolumn{7}{|c|}{ false-positive consensus evaluations } \\
\hline 1 & 58 & 4 & 1 & benign & course & $\begin{array}{l}\text { bronchial carcinoma initially diagnosed in } 2012 \text {, PET-CT } \\
2012 \text { without findings in the breast, consistent findings } \\
\text { in the target lesion in the } 4 \text {-year CT follow-up period }\end{array}$ \\
\hline 2 & 72 & 4 & 1 & benign & $\begin{array}{l}\text { senological } \\
\text { clarification }\end{array}$ & $\begin{array}{l}\text { breast-conserving therapy of a breast carcinoma in } 2004 \text {, } \\
\text { regular senologic-sonographic and X-ray-mammograph- } \\
\text { ic follow-up examinations until } 7 / 2015\end{array}$ \\
\hline 3 & 61 & 4 & 1 & benign & course & $\begin{array}{l}\text { breast-conserving therapy of a breast carcinoma in } 1997 \text {, } \\
\text { initial diagnosis of osseous metastases in } 2008 \text {, no ma- } \\
\text { lignant breast tumor in the } 1 \text {-year clinical course }\end{array}$ \\
\hline 4 & 73 & 4 & 1 & benign & $\begin{array}{l}\text { senological } \\
\text { clarification }\end{array}$ & $\begin{array}{l}\text { elevated tumor markers and weight loss of unclear etiol- } \\
\text { ogy, senologic-sonographic and X-ray-mammographic } \\
\text { diagnosis BI-RADS } 2\end{array}$ \\
\hline 5 & 73 & 4 & 1 & benign & course & $\begin{array}{l}\text { ablation due to breast carcinoma in } 2000 \text {, pulmonary, } \\
\text { osseous, and hepatic metastases, consistency of findings } \\
\text { in the target lesion in the } 1.5 \text {-year CT follow-up period }\end{array}$ \\
\hline 6 & 83 & 4 & 1 & benign & course & $\begin{array}{l}\text { malignant melanoma Clark level IV tumor thickness } \\
1.5 \mathrm{~mm} \text {, initial diagnosis in 2012, consistency of findings } \\
\text { in the target lesion in the 2-year CT follow-up period }\end{array}$ \\
\hline 7 & 57 & 4 & 1 & benign & $\begin{array}{l}\text { senological } \\
\text { clarification }\end{array}$ & $\begin{array}{l}\text { metastasized bronchial carcinoma initially diagnosed in } \\
\text { 2012, biliary sepsis, senologic-sonographic and X-ray- } \\
\text { mammographic diagnostic imaging in 2012, BI-RADS } 2\end{array}$ \\
\hline 8 & 70 & 4 & 2 & benign & course & $\begin{array}{l}\text { malignant melanoma Clark level IV tumor thickness } \\
2.4 \mathrm{~mm} \text {, initial diagnosis in 2012, consistency of findings } \\
\text { in the target lesion in the } 4 \text {-year CT follow-up period }\end{array}$ \\
\hline 9 & 48 & 4 & 2 & benign & $\begin{array}{l}\text { senological } \\
\text { clarification }\end{array}$ & $\begin{array}{l}\text { breast carcinoma in 2010, with breast-conserving } \\
\text { therapy on the left and ablation on the right, osseous } \\
\text { metastasis in 2011, senologic-sonographic and X-ray- } \\
\text { mammographic follow-up 2012: BI-RADS 2, 1-year } \\
\text { X-ray-mammographic follow-up period BI-RADS 2, } \\
\text { consistency of findings in 1-year CT follow-up period }\end{array}$ \\
\hline 10 & 68 & 4 & 4 & benign & course & $\begin{array}{l}\text { breast-conserving therapy of a breast carcinoma in } 1995 \text {, } \\
\text { initial diagnosis of leiomyosarcoma in 2012, no malig- } \\
\text { nant breast tumor in the 2-year clinical course }\end{array}$ \\
\hline 11 & 45 & 4 & 4 & benign & course & $\begin{array}{l}\text { malignant melanoma tumor thickness } 1.22 \mathrm{~mm} \text {, initial } \\
\text { diagnosis in 2012, no breast carcinoma in the } 4 \text {-year } \\
\text { clinical course }\end{array}$ \\
\hline 12 & 72 & 4 & 4 & benign & $\begin{array}{l}\text { senological } \\
\text { clarification }\end{array}$ & $\begin{array}{l}\text { breast-conserving therapy of a breast carcinoma in } 1994 \text {, } \\
\text { pelvic leiomyosarcoma in 2012, no breast carcinoma in } \\
\text { the } 2.5 \text {-year clinical course }\end{array}$ \\
\hline 13 & 68 & 5 & 1 & benign & $\begin{array}{l}\text { senological } \\
\text { clarification }\end{array}$ & $\begin{array}{l}\text { breast-conserving therapy of a breast carcinoma in } 2007 \text {, } \\
\text { osseous (initial diagnosis in 2010) and hepatic (initial } \\
\text { diagnosis in 2011) metastases, consistency of findings } \\
\text { in the 6-month CT follow-up period, no malignant breast } \\
\text { tumor in the 12-month clinical course }\end{array}$ \\
\hline \multicolumn{7}{|c|}{ false-negative written reports } \\
\hline 1 & 73 & 5 & 1 & malignant & $\begin{array}{l}\text { histological } \\
\text { workup }\end{array}$ & $\begin{array}{l}\text { intramammary metastasis of a malignant melanoma } \\
\text { Clark level IV tumor thickness } 1.74 \mathrm{~mm}\end{array}$ \\
\hline 2 & 65 & 5 & 1 & malignant & $\begin{array}{l}\text { histological } \\
\text { workup }\end{array}$ & $\begin{array}{l}\text { intramammary metastases of a breast carcinoma, disse- } \\
\text { minated pulmonary, pleural, hepatic metastases }\end{array}$ \\
\hline
\end{tabular}



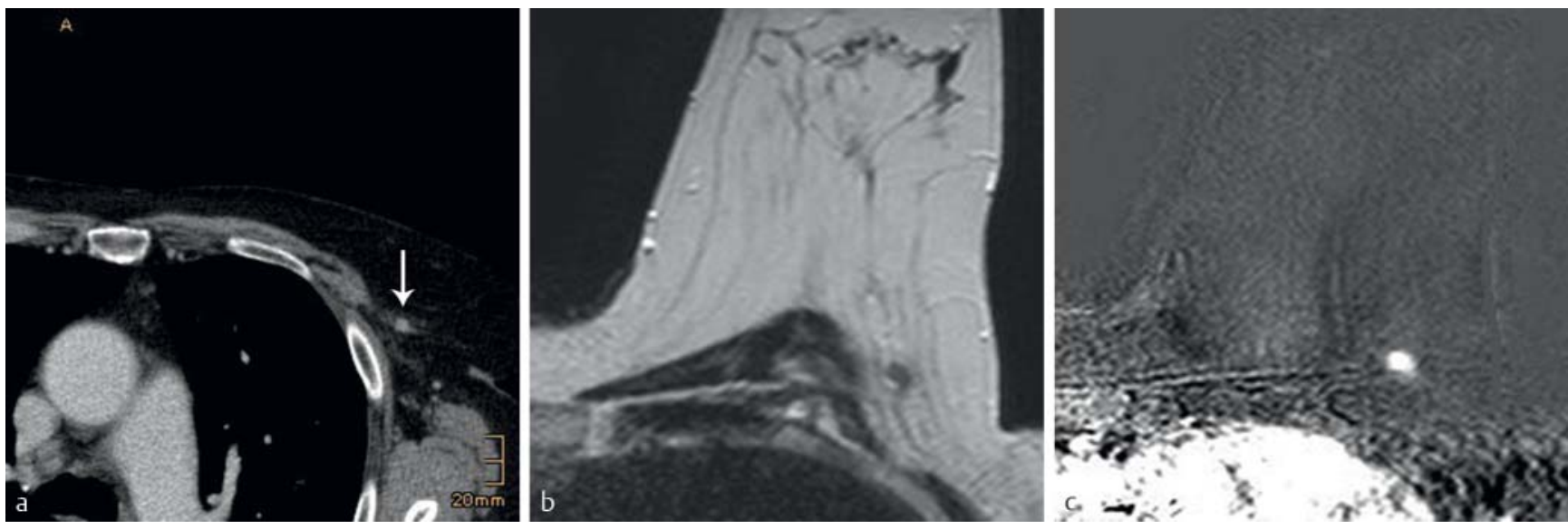

- Fig. 1 74-year-old patient with hematogenous metastasis of a malignant melanoma in the left breast missed in the written CT report. 2 hematogenous metastases had been resected in the left breast 16 months before. The index CT visualized a new focal contrast-enhanced lesion in the axillary part of the left breast $\mathbf{a}$. 10 days later MR mammography indicated as regular follow-up showed a mass lesion with intense early contrast enhancement typical for malignancy $\mathbf{b}$. After exploratory surgery the histological workup of the operative specimen yielded a new metastasis of the malignant melanoma. Arrow = mass lesion. a Index CT examination. b MR mammography, T2-weighted image. c MR mammography, contrast-enhanced subtraction image.
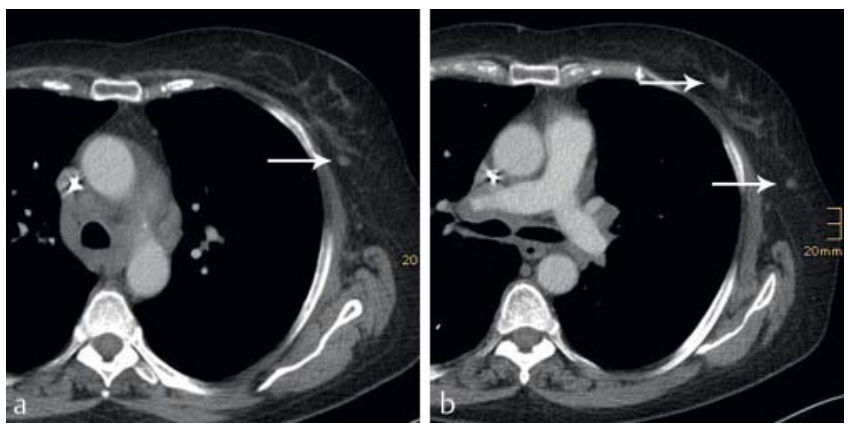

- Fig. 2 65-year-old patient suffering from intramammary metastases of a bilateral poorly differentiated invasive ductal breast cancer which were not noted in the written report of the CT examination. The written report focussed on mediastinal, axillary, chest wall, hepatic and bone metastases. There was a history of ablation of the right mamma and of breast conserving therapy of the left mamma. Metastases in the left breast were diagnosed 4 weeks following index-CT by ultrasonographically guided transcutaneous breast biopsy. Arrow = mass lesion. a Transverse slice acquired directly caudal to the mammillary plane. b Transverse slice $5 \mathrm{~cm}$ caudal to $\mathbf{a}$.

in benign tumors and an unsharp or spiculated margin and an inhomogeneous matrix were most often seen in malignant tumors $(p<0.001)$. Both density measurements within the lesions and their normalization in relation to the density of the pectoral muscle resulted in a statistically insignificant tendency toward higher densities in malignant tumors $(p=0.072 ; p=0.071)$.

\section{Discussion}

Contrast-enhanced multidetector computed tomography (MDCT) on conventional whole-body units is not used in the early detection and local staging of breast carcinomas due to its low spatial resolution compared to X-ray mammography not allowing evaluation of microcalcifications, its inferior contrast resolution compared to ultrasound and MR mammography (MRM), and its radiation exposure that is high compared to the other methods and is not limited to the breast region. Therefore, publications using a prospective approach to determine the diagnostic value of MDCT in the breast region are rare.

- Prior to histological verification, Uematsu T et al. performed contrast-enhanced MDCT, contrast-enhanced MRM, ultrasound, and X-ray mammography in patients with suspicion of a breast carcinoma. X-ray mammography examinations were evaluated independently by two radiologists. In the case of divergent classifications, a consensus decision was made. There were 210 carcinomas in 201 patients. The T-stage ranged from Tis (20 carcinomas; $19 \%)$ and T1 (123; $59 \%)$ to T2 (47; $22 \%)$. 210 carcinomas (100\%) were detected on MR mammography, 209 carcinomas (99.5\%) on ultrasound, 208 carcinomas (98\%) on computed tomography, and 195 carcinomas (93\%) on Xray mammography. In the visualization of the local tumor size, MRM (76\%) was superior to CT (71\%; $\mathrm{p}=0.001)$, ultrasound (56\%; $\mathrm{p}<0.0001)$ and $X$-ray mammography (52\%; $<<0.0001)$. The tumors not detected by CT were 2 of 24 ductal carcinomas in situ (DCIS). The most common indications of malignancy were focal enhancement $(n=21 ; 21.5 \%)$, ductal enhancement (22; $23 \%$ ), and segmental (33; $34 \%$ ) contrast enhancement.

- Perrone A et al. used an MDCT protocol including data acquisition in minute 1,3 , and 8 after i. v. contrast agent administration to preoperatively examine 47 patients with suspicion of a breast carcinoma and contraindications to MRI [14]. Histological workup of the resected specimens yielded 20 benign findings, 6 DCISs, and 21 invasive carcinomas. On CT, 25 of 27 carcinomas and all benign lesions were detected and correctly assessed with respect to their biological significance. 2 DCISs detected on the basis of microcalcifications were not detected by CT. The accuracy of MDCT was $96 \%$. The time-density 


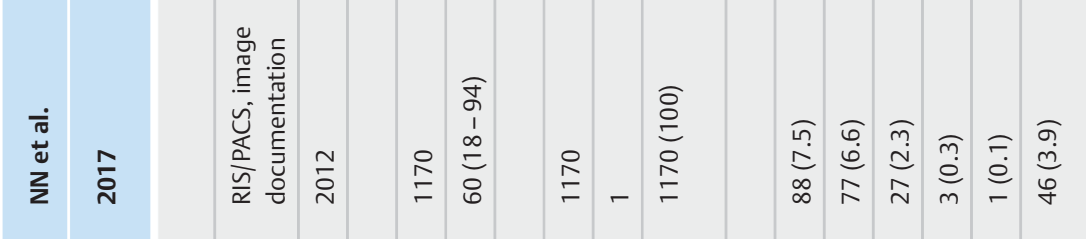

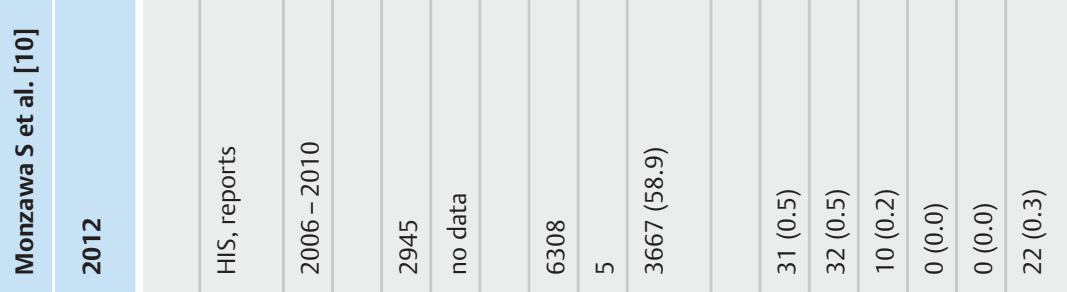

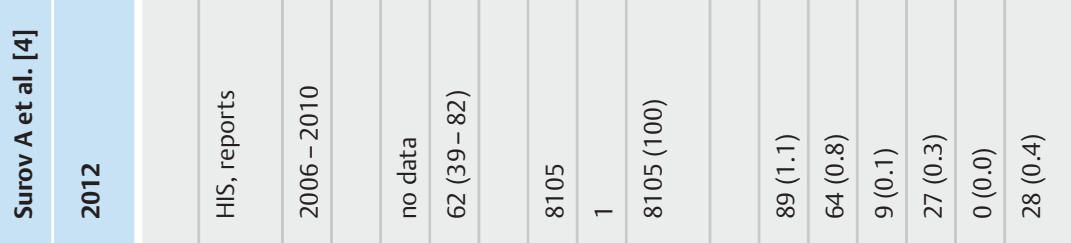

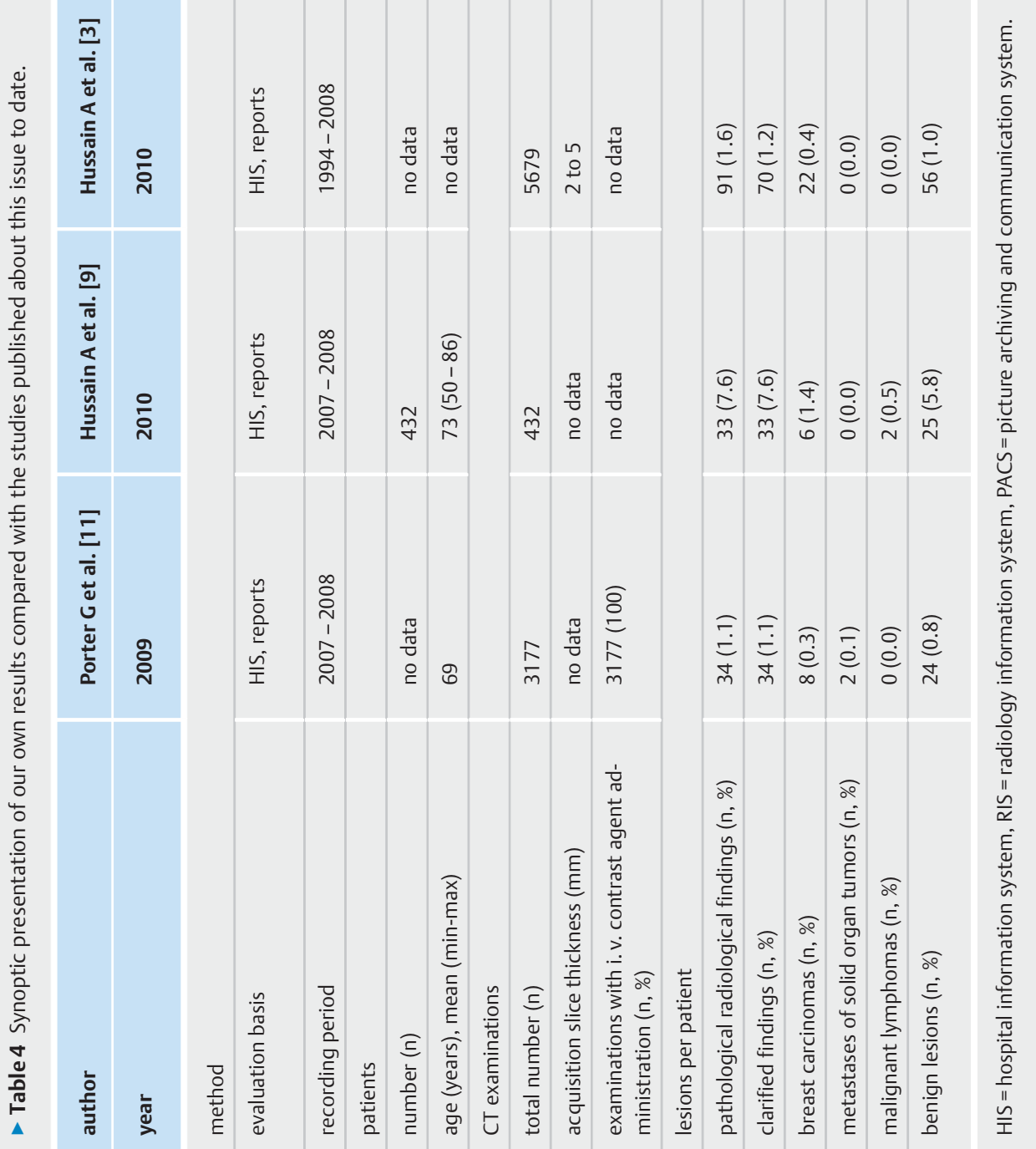



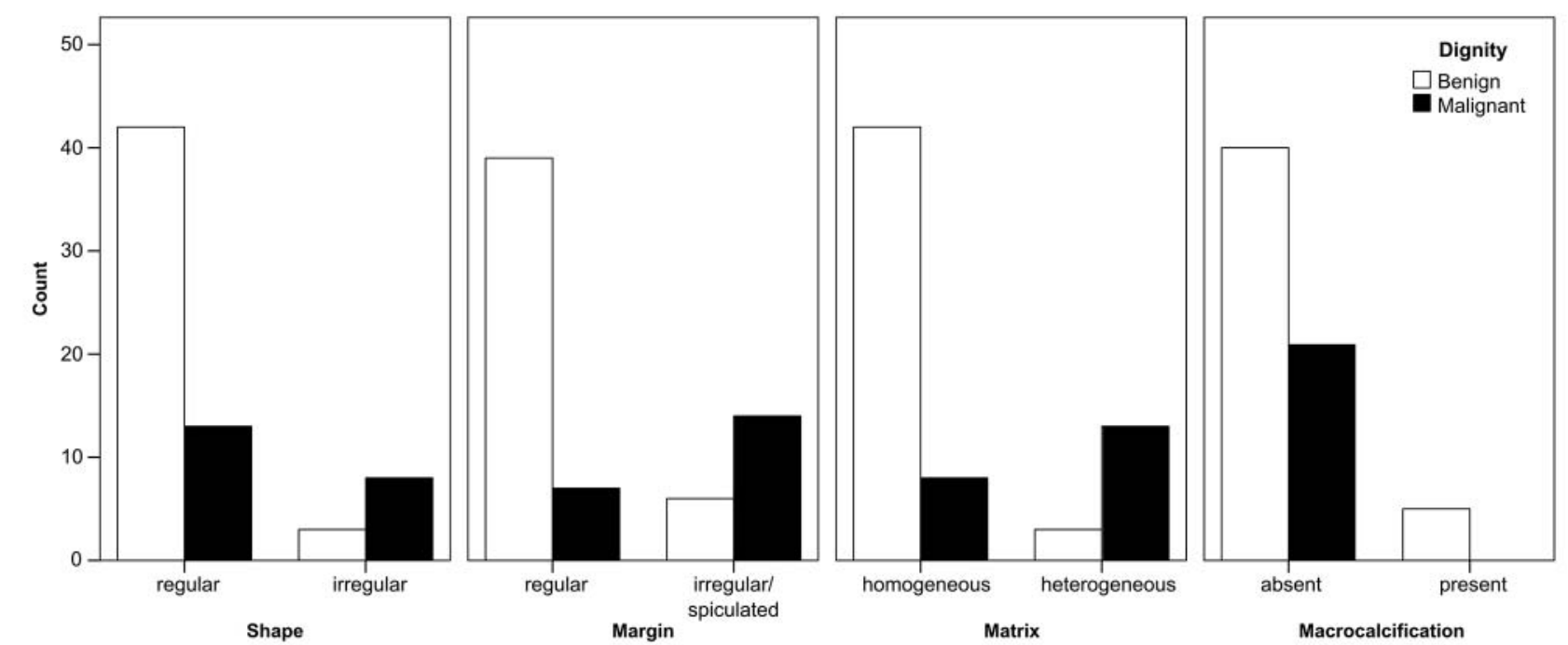

- Fig. 3 Frequency distribution of the discriminators on benign and malignant findings in the 78 index lesions with known biological potential. Irregular shapes $(p<0.01)$, irregular or spiculated margins $(p<0.001)$ and inhomogeneous matrices $(p<0.001)$ were more often seen in malignant than in benign pathologies.
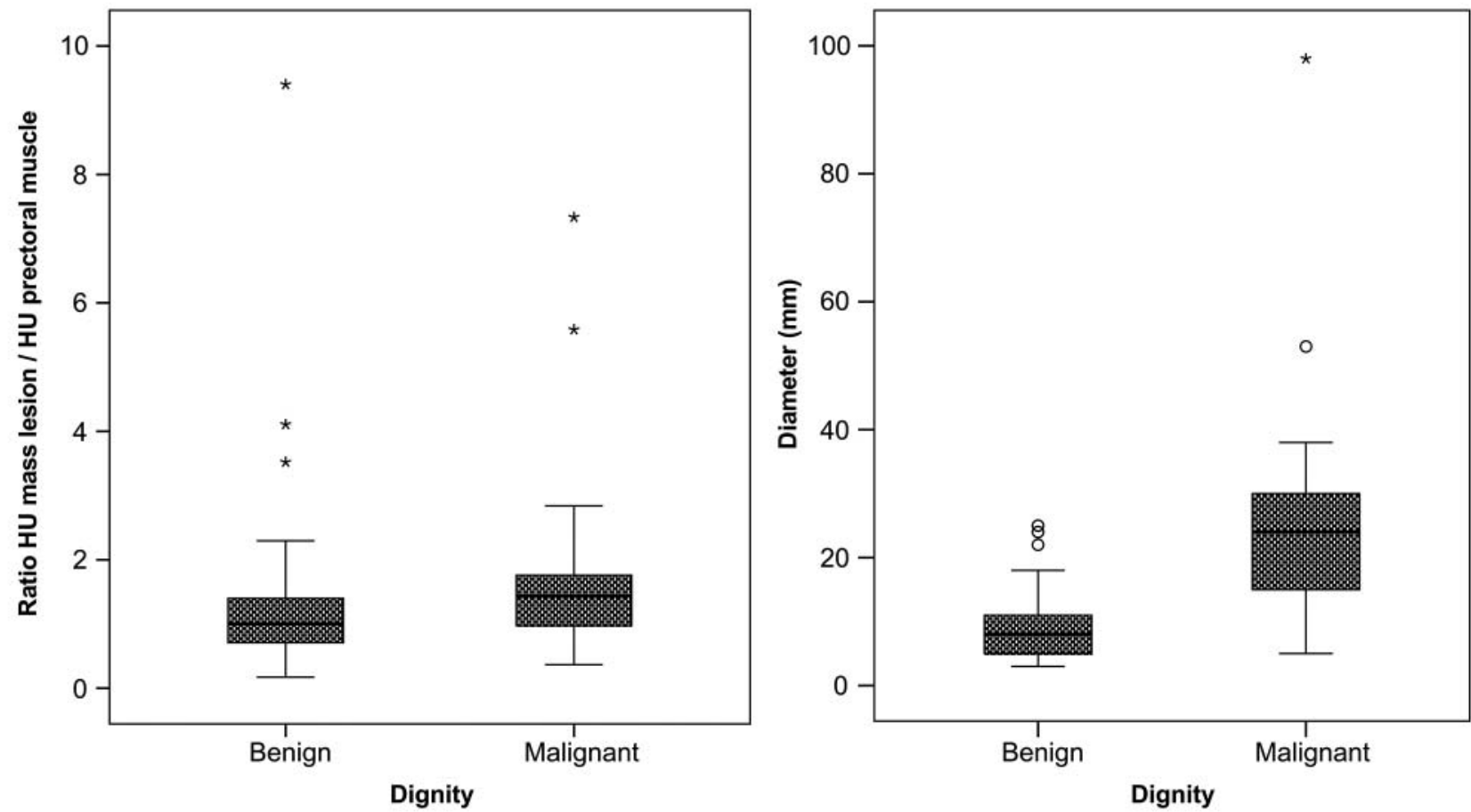

- Fig. 4 Box plot diagrams visualizing the quotient of densities measured in the index breast lesions and in the pectoralis musculature on the left side as well as the maximum lesion diameters on the right side stratified according to benign vs. malignant etiology in the 78 index lesions with known biological potential, respectively. Malignant lesions showed stronger enhancement compared to the pectoralis musculature $(p=0.071)$ as well as larger diameters $(p<0.001) .{ }^{*}=$ statistical outlier. 


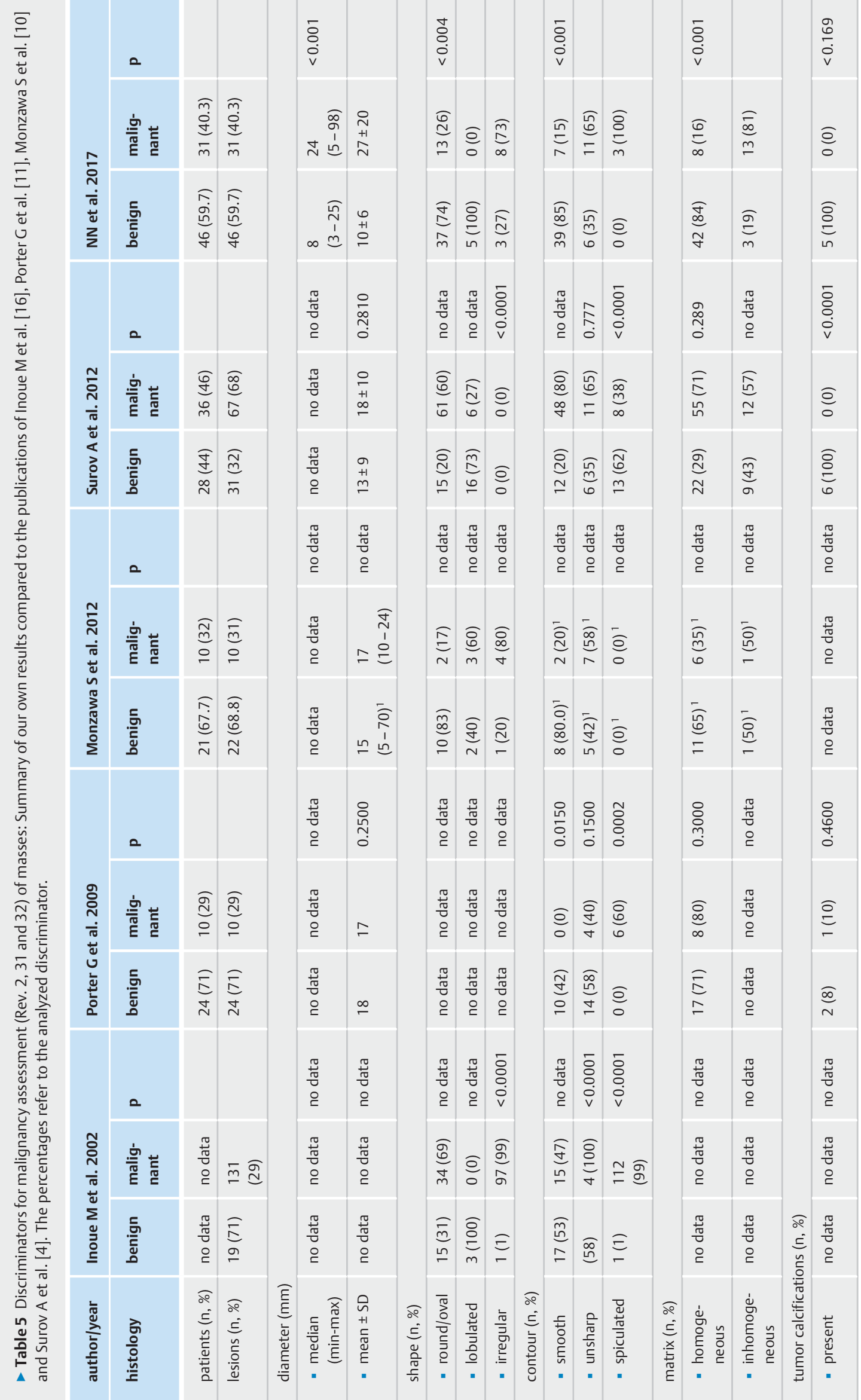




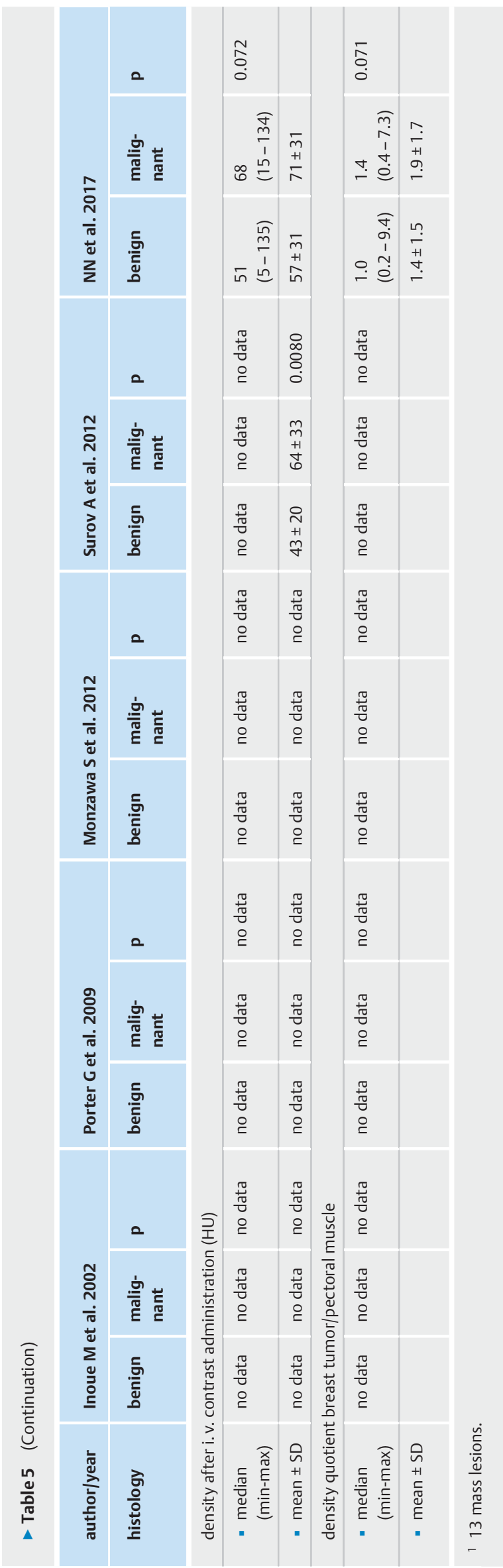

curves after i. v. contrast administration showed a tendency toward wash out in carcinomas and prolonged enhancement in benign lesions.

- Inoue M et al. conducted MDCT examinations using a comparable protocol in 149 patients with suspicion of a breast carcinoma [14]. All 173 detected breast lesions were histologically verified. 131 of 150 mass lesions (87\%) and 21 of 23 non-mass lesions (91\%) were malignant. 13 invasive breast carcinomas detected on MDCT were not detected on X-ray mammography and 5 carcinomas detected on CT were not detected on ultrasound. Analysis of the time-density curves after i. v. contrast administration confirmed the value of the curve known from MR mammography for differential diagnosis.

The potential of CT in diagnostic imaging of the breast shown by Uematsu T et al. [13], Perrone A. et al. [15], and Inoue M et al. [14] is taken into consideration in the current development of CT systems specifically designed for breast examinations. The first dedicated CT systems for the breast are currently being introduced by 2 companies (Koning Corporation, New York, USA; CT Imaging $\mathrm{GmbH}$, Erlangen, Germany). Whole-body MDCT technology cannot be used to evaluate issues primarily related to the parenchyma because of the comparatively high radiation exposure of the breast as well as any tissue in the beam path. Typical effective doses are specified as $0.2-0.6 \mathrm{mSv}$ for $\mathrm{X}$-ray mammography examination of both breasts and 5.0-7.0 mSv for CT examination of the chest $[16,17]$.

Senological information obtained from CT examinations of the chest performed due to pulmonary, hilar, and mediastinal issues should be regularly reviewed when evaluating findings and included in reporting. Probably as a result of the image-based approach, the percentage of BI-RADS 3 - 5 findings requiring further workup in the present study $(5.8 \%)$ was higher than in the case of Porter G. et al. (1.1\% of 3177 CT examinations), Moyle P et al. (1.6\% of 5679 CT examinations), Surov A et al. (1.1\% of 8105 CT examinations) and Monzawa S et al. (0.5\% of 6308 CT examinations) who based their evaluations on the retrospective analysis of written reports ( $\triangleright$ Table 5$)[3-5,11]$ Only Hussain A et al. [8] had a comparable result: $7.6 \%$ of 432 CT examinations with incidental findings in the breast. The number of BI-RADS 3 5 findings retrospectively histologically confirmed as malignant $(0.9 \%)$ was similar to that of Hussain A et al. (1.9\%) and higher than in the case of Porter $\mathrm{G}$ et al. (0.4\%), Moyle P et al. $(0.4 \%)$, Surov A et al. (0.4\%), and Monzawa $S$ et al. $(0.2 \%)[3-5,8,11]$. The differences are probably the result of different inclusion and exclusion criteria.

The presented evaluations confirm that the discriminators established for MR mammography [18, 19] for determining the biological significance of mass lesions and focal contrast enhancement (non-mass lesions) can be transferred to diagnostic CT imaging ( $\triangleright$ Table 5). Only microcalcifications could not be evaluated on CT due to the lower spatial resolution compared to $X$-ray mammography. Future prospective studies must determine the extent to which it is possible to increase the specificity of information regarding malignancy of an intramammary lesion using innovative $\mathrm{CT}$ technologies such as dual-energy or multi-energy methods. 
The presented study had the following method-related limitations with respect to method.

- The examined population is only representative of a maximum care hospital with a focus on oncology. In hospitals and radiology practices with a different clinical focus, changes in the prevalence and differential diagnostic spectrum of intramammary lesions can be expected due to variations in age distribution and disease rates.

- The incidence of clinically occult breast carcinomas remains unknown in the examined 1170 patients due to the retrospective approach of the study and the partially incomplete visualization of the body of the breast due to the CT examination technique used during treatment. Therefore, it is not possible to specify the number of false-negative CT findings in the examined population.

- It was possible to determine the differential diagnosis or the biological potential of the lesions diagnosed in the retrospective consensus evaluations in approximately half of the affected patients only on the basis of the clinical course or CT followup examinations.

The percentage of benign BI-RADS $1 / 2$ findings was $92.5 \%$ in the examined population of 1170 patients. Due to the retrospective approach and the partially incomplete visualization of the parenchyma, the percentage of undetected or clinically occult breast carcinomas could not be determined so that the prevalence of malignant breast tumors cannot be specified. The retrospectively determined BI-RADS $\geq 3$ findings were breast carcinomas (BI-RADS 6) already verified at the time of CT imaging in $1.7 \%$ (20 patients/CT examinations), BI-RADS 4/5 findings in $2.7 \%$ (32), and BI-RADS 3 findings in $3.1 \%$ (36). $1.1 \%$ (13) of the retrospectively recorded BI-RADS 4/5 findings were false-positive and $0.2 \%$ (2) were false-negative. The malignant breast tumors that were overlooked in primary reporting affected patients in advanced tumor stages and were not therapeutically and prognostically relevant. The prevalence of malignant breast lesions (940 per 100000 patients examined with CT) was approximately twice as high as in mammography screening $[20,21]$. The results of the study highlight the importance of targeted consideration of incidental senological findings in CT examinations of the chest also in other clinical settings than that of the included patients in a clinic with a main focus on oncology.

\section{Conflict of Interest}

The authors declare that they have no conflict of interest.

\section{References}

[1] Johnson KM, Dennis JM, Dowe DA. Extracardiac Findings on Coronary CT Angiograms: limited vs. complete image review. Am J Roentgenol 2010; 195: $142-148$
[2] Meller MT, Cox JE, Callanan KW. Incidental detection of breast lesions with computed tomography. Clin Breast Cancer 2007; 7: 634-637

[3] Moyle P, Sonoda L, Britton P et al. Incidental breast lesions detected on CT: what is their significance? $\mathrm{Br}$ J Radiol 2010; 83: $233-240$

[4] Surov A, Fiedler E, Wienke A et al. Intramammary incidental findings on staging computer tomography. Eur J Radiol 2012; 81: 2174-2178

[5] Yi JG, Kim SJ, Marom EM et al. Chest CT of incidental breast lesions. J Thoracic Imaging 2008; 23: 148-155

[6] Harish MG, Konda SD, MacMahon H et al. Breast lesions incidentally detected with CT: what the general radiologist needs to know. Radiographics 2007; 27: S37 - S51

[7] Shojaku $\mathrm{H}$, Seto $\mathrm{H}$, Iwai $\mathrm{H}$ et al. Detection of incidental breast tumors by noncontrast spiral computed tomography of the chest. Radiat Med 2008; 26: $362-367$

[8] Hussain A, Gordon-Dixon A, Almusavy $\mathrm{H}$ et al. The incidence and outcome of incidental breast lesions detected by computed tomography. Ann R Coll Surg Engl 2010; 92: 124-126

[9] Bach AG, Abbas J, Jasaabuu C et al. Comparison between incidental malignant and benign breast lesions detected by computed tomography: a systematic review. J Med Imaging Radiat Oncol 2013; 57: 529-533

[10] Monzawa S, Wasgio T, Yasuoka R et al. Incidental detection of clinically unexpected breast lesions by computed tomography. Acta Radiol 2013; 54: $374-379$

[11] Porter G, Steel ], Paisley K et al. Incidental breast masses detected by computed tomography: are any imaging features predictive of malignancy? Clinical Radiology 2009; 64: 529 - 533

[12] American College of Radiology. ACR BIRADS®-Atlas der Mammadiagnostik. Richtlinien zu Befundung, Handlungsempfehlungen udn Monitoring. Deutsche Übersetzuung der 5. Englischen Auflage. Berlin - Heidelberg: Springer Verlag. 2016

[13] Uematsu T, Yuen S, Kasami M et al. Comparison of magnetic resonance imaging, multidetector row computed tomography, ultrasonography, and mammography for tumor extension of breast cancer. Breast Cancer Res Treat 2008; 112: 461 - 474

[14] Perrone A, Mele LL, Sassi S et al. MDCT if the breast. Am J Roentgenol 2008; 190: $1644-1651$

[15] Inoue M, Sano T, Watai R et al. Dynamic Multidetector CT of Breast Tumors: Diagnostic Features and Comparison with Conventional Techniques. Am J Roentgenol 2003; 181: 679-686

[16] AAPM Report NO. 96. Report of a Task Group 23 of the Diagnostic Imaging Council CT Committee, January 2008. 2007 by American Association of Physicists in Medicine.

[17] Shannoun F, Blettner M, Schmidberger $\mathrm{H}$ et al. Strahlenschutz in der diagnostischen Radiologie. Deutsches Ärzteblatt 2008; 105: 41 - 46

[18] Baltzer P, Dietz M, Gröschel T et al. A simple and robust classification tree for differentiation between benign and malignant lesions in MRmammography. European Journal of Radiology 2012; 81: 4-5

[19] Dietzel M, Baltzer PA, Vag T et al. Differential diagnosis of breast lesions $5 \mathrm{~mm}$ or less: Is there a role for magnetic resonance imaging? J Comput Assist Tomogr 2010; 34: 456-464

[20] Simbach A, Wellmann I, Heidrich J et al. Trends in advanced cancer incidence rates after implementation of a mammography screening program in a German population. Cancer Epidemiology 2016; 44: 44- 51

[21] Weigel S, Batzler WU, Decker T et al. First epidemiological analysis of breast cancer incidence and tumor characteristics after implementation of population-based digital mammography screening. RöFo 2009; 181: $1144-1150$ 